\title{
A comparison of trans-fistula contrast-enhanced endoanal ultrasound and MRI in the diagnosis of anal fistula
}

\author{
Tao Lin ${ }^{1}$, Zhiying $\mathrm{Ye}^{2}$, Jingjing $\mathrm{Hu}^{2}$, Hua $\mathrm{Yin}^{2}$ \\ ${ }^{1}$ Department of Ultrasound in Medicine, The Second Affiliated Hospital of Zhejiang University School of Medicine, Zhejiang University, Hangzhou, \\ China; ${ }^{2}$ Department of Ultrasound in Medicine, Hwa Mei Hospital, University of Chinese Academy of Sciences, Ningbo, China \\ Contributions: (I) Conception and design: H Yin; (II) Administrative support: H Yin; (III) Provision of study materials or patients: T Lin, Z Ye, J Hu; \\ (IV) Collection and assembly of data: T Lin; (V) Data analysis and interpretation: T Lin; (VI) Manuscript writing: All authors; (VII) Final approval of \\ manuscript: All authors. \\ Correspondence to: Hua Yin. Hwa Mei Hospital, University of Chinese Academy of Sciences, No. 41, Northwest Street, Ningbo 315010 , China. \\ Email: jerry_yin@163.com.
}

\begin{abstract}
Backgrounda Many hospitals favor magnetic resonance imaging (MRI) as the preferred diagnostic method to detect anal fistula, trans-fistula contrast-enhanced ultrasound (CEUS) for the diagnosis of anal fistula have attracted the attention of investigators worldwide. This study aimed to investigate the efficacy of trans-fistula contrast-enhanced endoanal ultrasound (CEUS) and magnetic resonance imaging (MRI) in the diagnosis of anal fistula.
\end{abstract}

Methods: Ninety-eight patients undergoing trans-fistula CEUS and MRI were retrospectively analyzed. The fistulous trend and positional relation between the fistula, levator ani muscle, and sphincter (Parks classification), as well as the numbers of fistulous branches, number and position of the fistula, and distance between internal opening and anal edge were recorded. These parameters were compared with the postoperative results.

Results: There were no significant statistical differences $(\mathrm{P}>0.05)$ in the accuracy rates of trans-fistula CEUS and MRI, respectively, in terms of Parks classification (90.82\%, 92.86\%), branches (89.19\%, 81.08\%), internal openings $(92.68 \%, 89.43 \%)$, and internal openings $\geq 3 \mathrm{~cm}$ from the anal edge $(85.71 \%, 92.86 \%)$. However, we observed a significant difference in terms of internal openings $<3 \mathrm{~cm}$ from the anal edge (96.30\%, 87.65\%) (P=0.043).

Conclusions: Although both methods exhibited a perfect accuracy rate in diagnosing anal fistula, transfistula CEUS displayed superior diagnostic value for internal openings $<3 \mathrm{~cm}$ from the anal edge, and could provide reliable pre-operative evidence.

Keywords: Trans-fistula contrast-enhanced ultrasound; magnetic resonance imaging (MRI); anal fistula

Submitted Jun 04, 2021. Accepted for publication Aug 02, 2021.

doi: 10.21037/apm-21-1624

View this article at: https://dx.doi.org/10.21037/apm-21-1624

\section{Introduction}

Anal fistula, a granulomatous cavity, is caused by infection to the anal glands of the anal sinus near the dentate line. One of the reasons of anal fistula formation is recurrent perianal abscesses. Anal fistula, which has a prevalence that is second only to hemorrhoids, is a common disorder and is responsible for $3 \%$ of all anorectal diseases. Until recently, the main treatments of anal fistula were surgical or conservative therapy (1). Given that the accurate diagnosis of the fistula and the internal opening plays a key role in the surgical procedure, the pre-operative evaluation of fistula is significant in producing an ideal therapeutic effect $(2,3)$.

Currently, many hospitals favor magnetic resonance imaging (MRI) as the preferred diagnostic method to detect anal fistula, and have shown that it has good specificity and 
sensitivity for the detection of this lesion (4-7). In ultrasonic medicine, contrast-enhanced ultrasound (CEUS), a rapidly developing technique in recent years, utilizes the acoustic scattering of microbubbles to form a high contrast of acoustic impedance, increasing the image contrast between the fusion parts and surrounding tissues, and improves the diagnostic sensibility and specificity. Studies performing trans-fistula CEUS for the diagnosis of anal fistula have attracted the attention of investigators worldwide (8-10) However, debates have continued and no consensus has been reached among the experts on this topic. In this study, we aimed to investigate the diagnostic value of trans-fistula CEUS and MRI in classifying anal fistula [based on the Parks criteria (11)] and locating the internal opening. We present the following article in accordance with the STARD reporting checklist (available at https://dx.doi.org/10.21037/ apm-21-1624).

\section{Methods}

\section{Subjects}

This study enrolled 98 patients from the Anorectal Surgical Department, Hwa Mei Hospital, University of Chinese Academy of Sciences between February 2016 and December 2017. Enrolled patients included 68 males and 30 females with an average age of $38.75 \pm 10.54$ years (range, 1978 years). This study was approved by the ethics committee of Hwa Mei Hospital (YJ-KYSB-NBEY-2018-034-01), and informed consent was obtained from all patients. The study was conducted in accordance with the Declaration of Helsinki (as revised in 2013).

\section{Inclusion criteria}

The inclusion criteria were as follows: (I) patients who were clinically diagnosed with anal fistula; (II) the presence of only one perianal external opening; (III) patients who received MRI and trans-fistula CEUS examinations after admission; (IV) patients that provided informed consent; and $(V)$ patients who underwent surgery within 24 hours after trans-fistula CEUS examination, with a detailed operative report.

\section{Exclusion criteria}

The exclusion criteria were as follows: (I) patient who underwent surgery or seton treatment within two months prior to trans-fistula CEUS examination; and (II) patients with severe or uncontrolled infection, none or $\geq 2$ perianal external openings, low endurance for intracavity ultrasonic examination, and serious cardiac and pulmonary disorders and dysfunctions.

\section{Instruments}

The trans-fistula CEUS was performed with the Esaote MyLabTwice color ultrasound system (ESAOTE S.p.A.Italia) using a LA533 linear array probe $(3-13 \mathrm{MHz})$ and a TRT33 biplane probe (3-13 MHz). The MRI scan was performed using a Siemens AVANTO 1.5 T (Siemenss Ltd. Germany) superconducting magnet coupled with Siemens torso phased-array coil.

\section{Examination methods}

\section{Trans-fistula CEUS}

Visual and digital rectal examinations were performed prior to the trans-fistula CEUS examination. The area between the probes protected by disposable latex sets was smeared with the coupling medium. The outsides of the latex sets were smeared in the same way as the insides. Patients were examined in the left lateral position, with flexed hips and knees, and were instructed to take deep breaths to relax the anal muscles.

Firstly, we used a linear array probe to detect the perianal area by radial scanning. Following this, the endoanal ultrasound with biplanar probe was performed layer-bylayer from the anus to the distal of the rectum, and the probe was turned for circular scanning when the lesion appeared. Upon completion of the conventional ultrasonic anal examination, we placed a trochar hose approximately $5-10 \mathrm{~mm}$ into the fistulous external opening and injected an appropriate volume of SonoVue ${ }^{\circledR}$ suspension (Braacco Company, Italy). The SonoVue ${ }^{\circledR}$ suspension was prepared by injecting $5 \mathrm{~mL} 0.9 \%$ saline solution into the SonoVue ${ }^{\circledR}$ bottle, and $1 \mathrm{~mL}$ was extracted from the blended liquid using a $20 \mathrm{~mL}$ injector. We then added saline solution into the $1 \mathrm{~mL}$ of blended liquid until the volume was $20 \mathrm{~mL}$, and the prepared liquid was hermetically sealed and oscillated sufficiently. We subsequently used the scanning probe to trace the bubble along the fistula, stored at least 20 second-dynamic ultrasound images, and watched the video recording carefully to recognize the bubble movement in the fistula. 
A

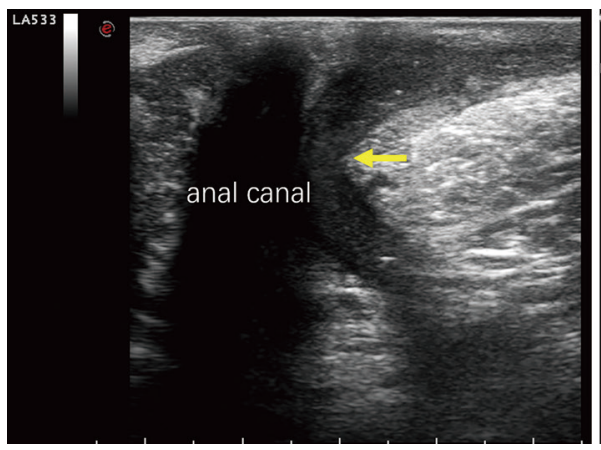

B

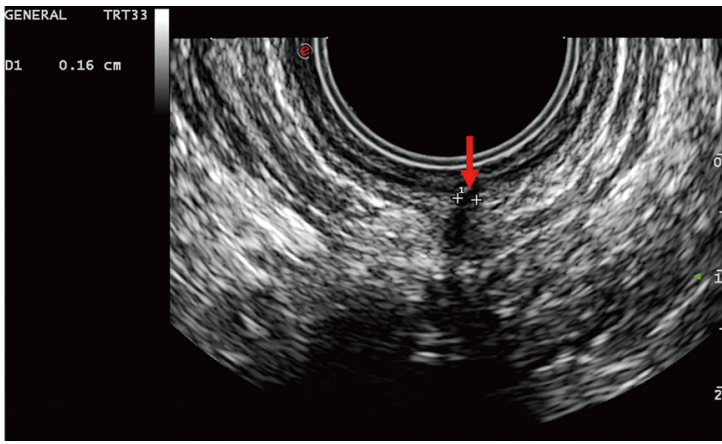

Figure 1 Conventional ultrasound image of the fistula and the internal opening. (A) Conventional ultrasound image of the fistula (yellow arrow); (B) conventional ultrasound image of the internal opening (red arrow).

\section{MRI scan}

Patients were examined in the supine position and eupnea. Images of the rectum were obtained by $\mathrm{T} 1$-weighted (T1WI), T2-weighted (T2WI), fat-saturation T2WI (FsT2WI), and T1-weighted enhanced (T1WI + C) sequences in three orthogonal imaging planes (axial, coronal, and sagittal). The enhanced images were obtained by injecting a gadolinium enhancement agent $(0.1 \mathrm{mmol} / \mathrm{kg}$, GadoliniumDTPA) into the cubital vein using a high-pressure injector. The axial slices were performed orthograde to the anal canal, while the coronal sequences were performed parallel to the anal canal (parameters: $4 \mathrm{~mm}$ slice thickness with $0.5 \mathrm{~mm}$ skip; $512 \times 512$ size matrix).

In the above examination, we recorded the external opening position (lithotomy position using the clock method), main fistulous trend, Parks criteria classification, number of branches, position of branches, and distance between fistula and the anal edge. An experienced radiologist performed the trans-fistula CEUS examination, and the imaging data were evaluated using the doubleblind method by two experienced radiologists who were unaware of the patient's medical history. In cases of any discrepancy, consensus was reached by discussion between the radiologists.

\section{Evaluation criteria}

\section{Diagnosis of anal fistula using the conventional} ultrasound

The ultrasound images of a fistula show a hypoechoic or anechoic region with internal opening when the hypoechoic or anechoic region is traced inward, and external opening when the hypoechoic or anechoic region is traced outward
(Figure $1 A, 1 B$ ). The ultrasound images of the internal openings show mucous membrane disruption, local mucosal protrusion, or local mucosal depression.

\section{Diagnosis of anal fistula using trans-fistula CEUS}

The ultrasound images of the fistula show punctate or streak echo, which represent a bubble (enhanced agent) in the fistula, and this bubble could flow into the internal opening from the main fistula or fistulous branches. The hyperechoic enhanced agent flows into the rectal cavity from the disrupted mucous membrane and marks the internal opening (Figure 2A,2B).

\section{Diagnosis of anal fistula using MRI}

The fistula and its branches appear as streaks in the MRI, low or equal signal intensity in T1WI, high or slightly high signal intensity in Fs-T2WI, and the edge of fistula enhancement in T1WI + C. One side of the internal opening is the fistula and the other side of the opening is the rectal cavity. The MRI shows local mucosal protrusion and local mucosal disruption with high $\mathrm{T} 1$ and $\mathrm{T} 2$ signal intensity (Figure $3 A, 3 B$ ).

\section{Parks classification system (11)}

This classification system divides anal fistulas into four classes: (I) intersphincteric fistula (Is), where the fistula extends into the space of the sphincter, the end is on the surface of the external sphincter and subcutaneous tissue, the external opening is around the anus, and the secondary fistula and adjacent sinus are identifiable; (II) transsphincteric fistula (Ts), where the fistula passes through the internal and external sphincters and can be divided into high, middle, and low according to the position of 
A

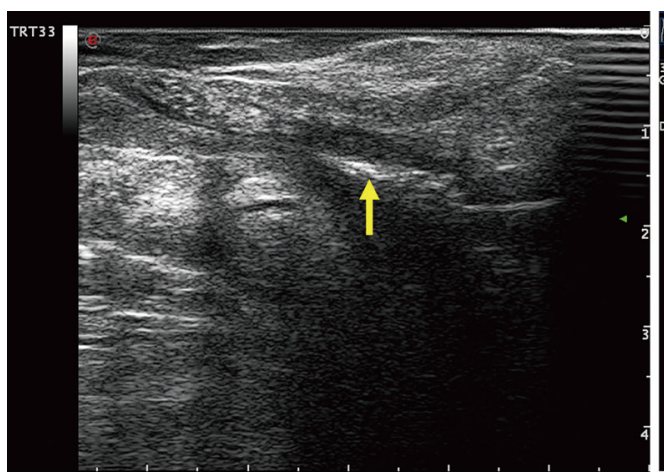

B

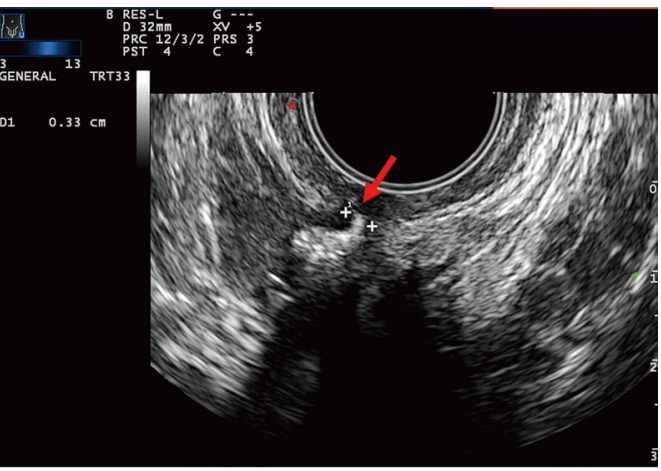

Figure 2 Trans-fistula CEUS echo image of the fistulous punctate and streak. (A) Trans-fistula CEUS echo image of the fistulous punctate (yellow arrow); (B) Trans-fistula CEUS echo image of streak (red arrow). CEUS, contrast-enhanced endoanal ultrasound.
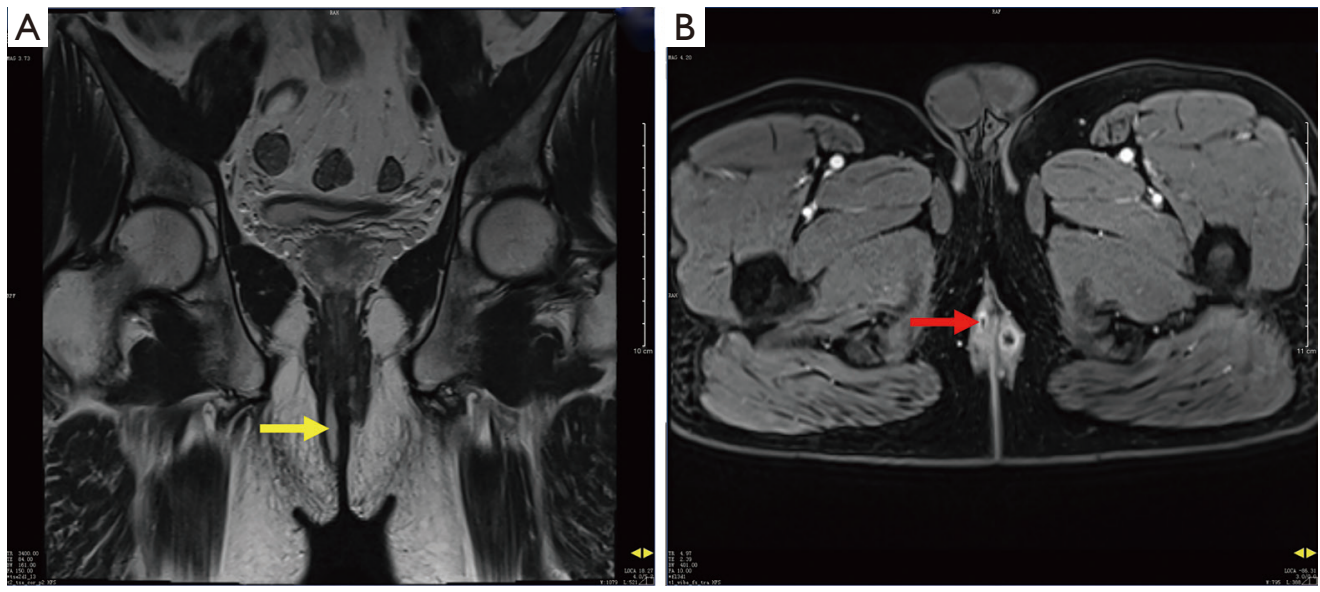

Figure 3 MRI image of a fistula tract and the internal opening. (A) MRI image of a fistula tract (yellow arrow); (B) MRI image of the internal opening (red arrow). MRI, magnetic resonance imaging.

the external sphincter; (III) suprasphincteric fistula (Ss), where the fistula lies above the sphincter and pierces the internal sphincter, spreading through the levator ani muscle upwardly and the sciatic rectum into the skin downwardly; (IV) extrasphincteric fistula (Es), where the fistula is located in the rectal fossa (flank of the sphincter) and communicates directly with the rectum through the levator ani muscle.

\section{Statistical method}

Statistical analysis was performed using SPSS version 19.0 (IBM. United States of America). Categorical data were expressed as numbers (percentage), and comparison of categorical variables was performed using the $\chi^{2}$ test. The gold standard was the operative diagnosis in the surgical report. We calculated the accuracy rates of MRI and transfistula CEUS in the diagnosis of anal fistula in terms of Parks criteria, branch of fistula, and the internal opening. P value $<0.05$ was considered statistically significant.

\section{Results}

\section{Accuracy rate of MRI and trans-fistula CEUS in classifying anal fistula}

Among the 98 patients who underwent surgery, 53 were classified as Is, 35 as Ts, 4 as Ss, and 6 as Es. The accuracy rates of MRI and trans-fistula CEUS in classifying anal fistula (Parks classification) were 92.68\% (91/98) and 
Table 1 MRI-base and trans-fistula CEUS-base parks classification comparing with surgical diagnosis

\begin{tabular}{|c|c|c|c|c|c|c|c|c|}
\hline Surgical diagnosis & \multicolumn{4}{|c|}{ MRI scan } & \multicolumn{4}{|c|}{ Trans-fistula CEUS } \\
\hline Is ${ }^{*}(n=53)$ & 51 & 2 & 0 & 0 & 50 & 2 & 0 & 1 \\
\hline $\mathrm{Ts}^{*}(\mathrm{n}=35)$ & 2 & 32 & 1 & 0 & 1 & 32 & 1 & 1 \\
\hline $\mathrm{Ss}^{*}(\mathrm{n}=4)$ & 0 & 1 & 3 & 1 & 0 & 0 & 2 & 2 \\
\hline Sum $(n=98)$ & 53 & 35 & 4 & 6 & 51 & 34 & 4 & 9 \\
\hline
\end{tabular}

*: Is, intersphincteric fistula; Ts, transsphincteric fistula; Ss, suprasphincteric fistula; Es, extrasphincteric fistula. MRI, magnetic resonance imaging; CEUS, contrast-enhanced endoanal ultrasound.

Table 2 The accuracy, specificity, sensitivity, positive/negative predictive value (\%) in fistulous diagnosis by MRI and trans-fistula CEUS

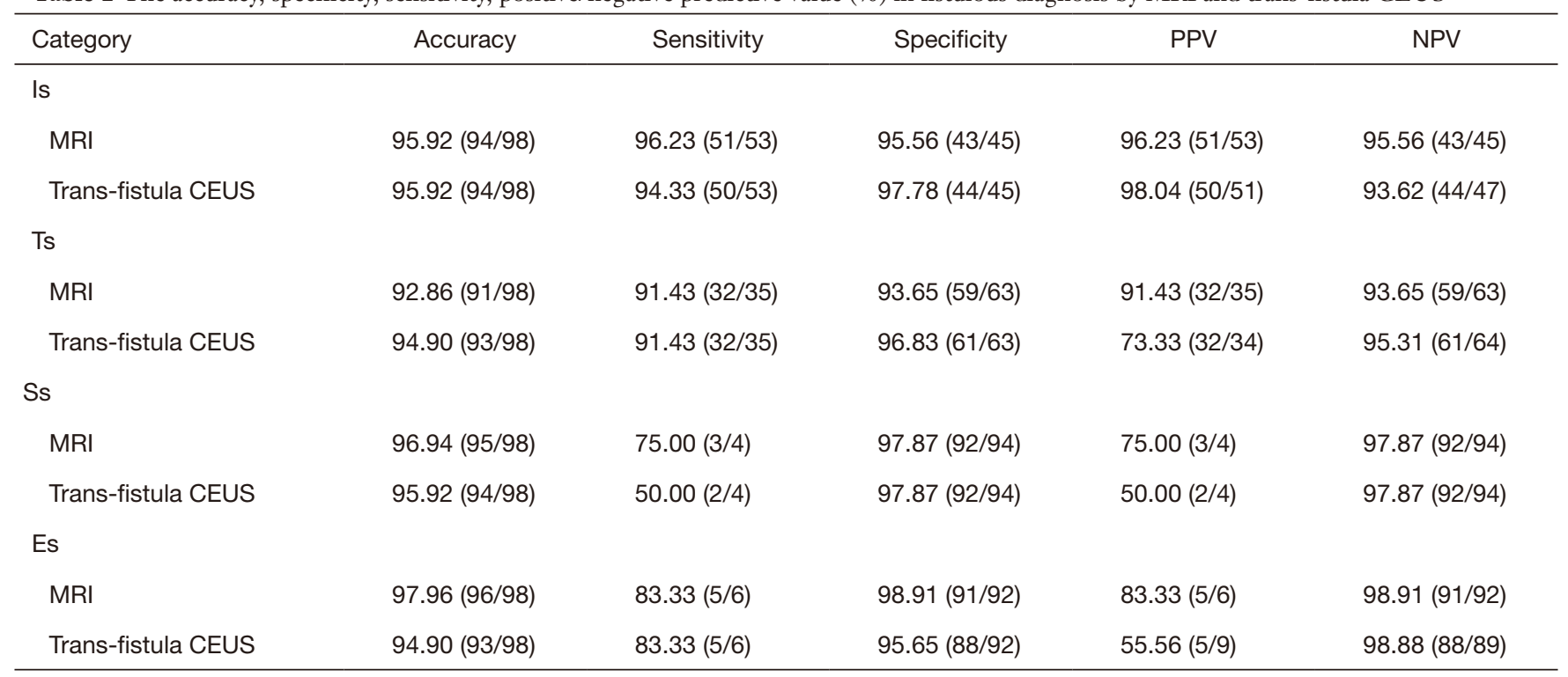

PPV, positive predictive value; NPV, negative predictive value; MRI, magnetic resonance imaging; CEUS, contrast-enhanced endoanal ultrasound.

$90.82 \%$ (89/98), respectively, and the difference was not statistically significant $\left(\chi^{2}=0.272, \mathrm{P}=0.602\right.$, Tables $\left.1-3\right)$.

\section{Accuracy rate of MRI and trans-fistula CEUS in detecting branches}

Of the 98 patients who underwent surgery, 37 branches were found intraoperatively, 33 were detected by MRI, and 30 were detected by trans-fistula CEUS. There were no statistically significant differences in the accuracy rates between the two examinations (MRI 86.49\% and transfistula CEUS $81.08 \%)\left(\chi^{2}=0.961, P=0.327\right)$.

\section{Accuracy rate of MRI and trans-fistula CEUS in detecting internal openings}

Of the 98 patients who accepted surgery, 137 internal openings were found intraoperatively, where 80 patients had one internal opening each, 12 patients had two internal openings each, five patients had three internal openings each, and one patient had four internal openings. MRI revealed 110 internal openings, with no internal opening detected in 10 patients, 73 patients with one internal opening each, nine patients with two internal openings each, five patients with three internal openings each, and one patient with four internal openings. In contrast, trans- 
Table 3 The accuracy rates (\%) in diagnosing fistulous Parks classification by MRI and trans-fistula CEUS

\begin{tabular}{|c|c|c|c|c|}
\hline Variables & MRI, (n=98) (\%) & Trans-fistula CEUS, $(n=98)(\%)$ & $\chi^{2}$ & $P$ value \\
\hline
\end{tabular}

MRI, magnetic resonance imaging; CEUS, contrast-enhanced endoanal ultrasound.

Table 4 The accuracy rates (\%) in diagnosing fistulous branches by MRI and trans-fistula CEUS

\begin{tabular}{|c|c|c|c|c|}
\hline Variables & MRI (\%) & Trans-fistula CEUS (\%) & $\chi^{2}$ & $P$ value \\
\hline Accuracy of internal opening $(n=123)$ & 110/123 (89.43) & $114 / 123(92.68)$ & 0.799 & 0.371 \\
\hline Accuracy of distance $<3 \mathrm{~cm}(\mathrm{n}=81)$ & $71 / 81(87.65)$ & $78 / 81(96.30)$ & 4.098 & 0.043 \\
\hline Accuracy of distance $\geq 3 \mathrm{~cm}(\mathrm{n}=42)$ & $39 / 42(92.86)$ & $36 / 42(85.71)$ & 1.120 & 0.290 \\
\hline
\end{tabular}

$\mathrm{MRI}$, magnetic resonance imaging; CEUS, contrast-enhanced endoanal ultrasound.

fistula CEUS displayed 114 internal openings, with no internal opening was detected in five patients, 78 patients with one internal opening each, 10 patients with two internal openings each, four patients with three internal openings each, and one patient with four internal openings. The overall accuracy rates of MRI and trans-fistula CEUS were $89.43 \%$ and $92.68 \%$, respectively, and the difference was not statistically significant $\left(\chi^{2}=0.799, \mathrm{P}=0.371\right)$.

Of all 123 internal openings detected, the average distance between the fistulous internal opening and anal edge was $2.96 \pm 0.73 \mathrm{~cm}$ (range 0.8 to $5.3 \mathrm{~cm}$ ). In the surgical results, the distances between the internal opening and the anal edge were $<3 \mathrm{~cm}$ in 81 patients and $\geq 3 \mathrm{~cm}$ in 42 patients. In the MRI examinations, this distance was $<3 \mathrm{~cm}$ in 71 patients and $\geq 3 \mathrm{~cm}$ in 39 patients, while in the trans-fistula CEUS, it was $<3 \mathrm{~cm}$ in 78 patients and $\geq 3 \mathrm{~cm}$ in 36 patients. The trans-fistula CEUS had a higher accuracy rate of detection than MRI in patients with an internal opening $<3 \mathrm{~cm}$ from the anal edge (MRI versus trans-fistula CEUS: $87.65 \%$ versus $96.30 \%, \chi^{2}=4.098$, $\mathrm{P}=0.043)$. However, in patients whose internal opening was $\geq 3 \mathrm{~cm}$ from the anal edge, the difference in accuracy rates between MRI and trans-fistula CEUS (MRI versus transfistula CEUS: $92.86 \%$ versus $85.71 \%$ ) were not statistically significant $\left(\chi^{2}=1.120, \mathrm{P}=0.290\right)$ (Table 4; Figure 4A,4B; Figure $5 A, 5 B)$.

\section{Discussion}

Anal fistula and perianal abscesses are different pathological stages of one disease (12). Generally, they do not follow a natural recovery path; therefore, surgery is the fundamental treatment plan for this illness. However, the recurrence rate of anal fistula is high (13) and variable in different studies, and recurrence is commonly reported within 1 year of surgery (14). Also, 30-50\% of anal fistulas recur after oneoff surgery and often result in multiple operations (15). Clinically, the main target when treating anal fistula is to reduce the recurrence rate and protect anal function. Hence, the key challenge in increasing the success rate of one-off surgery is diagnosing the position of fistula, the positional relationship between the fistula, sphincter, and levator ani muscle, and accurate localization of the internal opening.

MRI offers numerous advantages, including excellent soft-tissue resolution, multiple plane scanning, and direct three-dimensional imaging. It can also obtain high-quality images and precisely depict perianal anatomical structure owing to the immobile feature of pelvic organs. Thus, MRI can display the location of the fistula, sphincter, and levator ani muscle, and provide reliable evidence for preoperative diagnosis and postoperative evaluation of the treatment efficacy. According to Sugrue et al., the sensitivity and specificity of MRI in identifying internal openings were $97.7 \%$ and $98.6 \%$, respectively, and the sensitivity and specificity of MRI in diagnosing fistula tracts were $98.8 \%$ and $99.7 \%$, respectively (14). An increasing number of hospitals are currently applying MRI for the pre-operative diagnosis of anal fistula. However, the high cost, low repeatability, and the body's adverse reaction to the MRI contrast agent limit its application in this field (16-18).

In 2011, the American Society of Colon and Rectal 

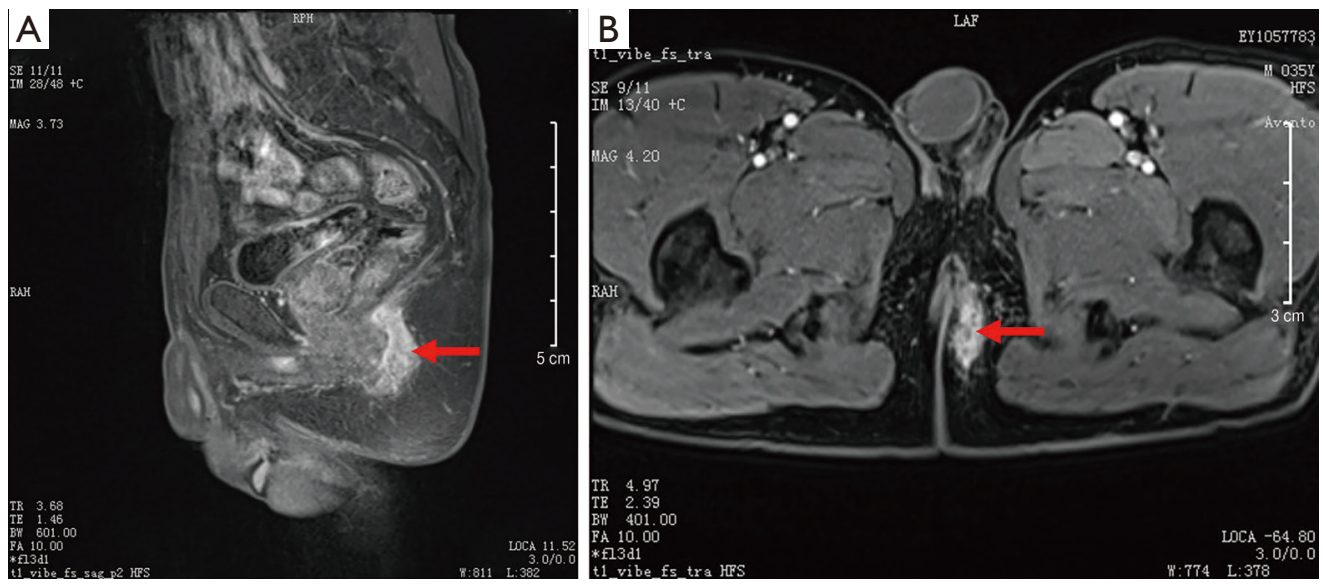

Figure 4 Enhanced MRI detected an enhanced fistula (red arrow) with no fistulous internal opening, which was diagnosed as an intersphincteric fistula. (A) Sagittal plane of the intersphincteric fistula in MRI image; (B) transverse plane of the intersphincteric fistula in MRI image. MRI, magnetic resonance imaging.

A

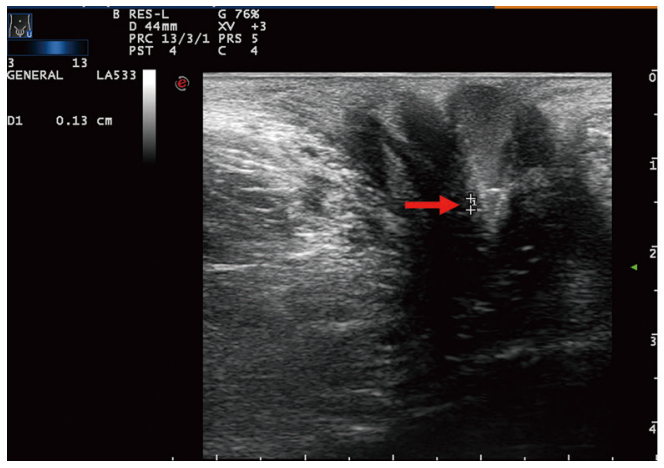

B

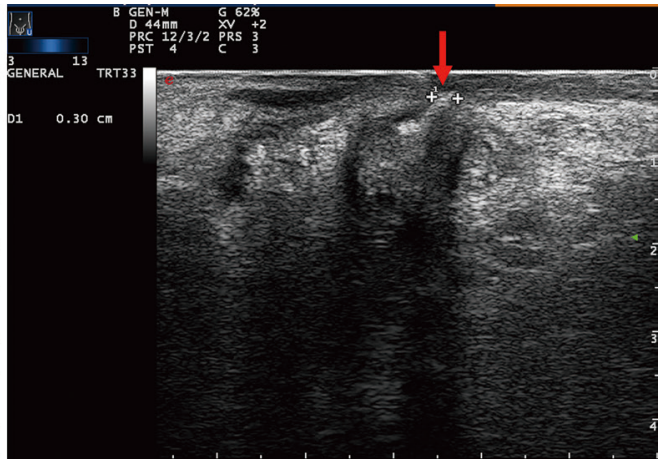

Figure 5 CEUS image of the same patient in Figure 4. Trans-fistula CEUS detected a fistula and an internal opening with lithotomy position, 6 o'clock position (red arrow). The images depicted hyperechoic enhanced agent flow into the anal canal and were diagnosed as intersphincteric fistula. (A) CEUS image obtained by surface linear array probe; (B) CEUS image obtained by high-frequency linear array probe coupled with biplane probe. CEUS, contrast-enhanced endoanal ultrasound.

Surgeons recommended ultrasound as a routine preoperative practice owing to its simple operation, low cost, and noninvasive feature. CEUS, a rapidly developing technique in recent years, utilizes the acoustic scattering of microbubbles to form a high contrast of acoustic impedance, increasing the image contrast between the fusion parts and surrounding tissues, and improves the diagnostic sensibility and specificity. This study was based on the routine ultrasound practice and performed trans-fistula CEUS to clarify the Parks classification of the lesion, fistulous branches, and the internal opening. As a result, the respective accuracy rates of trans-fistula CEUS and MRI to evaluate the Parks classification of the lesion were $92.68 \%$ and $89.43 \%$, to diagnose fistulous branches were $89.19 \%$ and $81.08 \%$, and to locate the internal opening were $92.88 \%$ and $89.43 \%$. There was no statistical difference between the results above (all $\mathrm{P}>0.05$ ), indicating that both diagnostic methods have equal efficiency in diagnosing anal fistula.

Furthermore, the diagnostic accuracy of trans-fistula CEUS was better than conventional ultrasound for anal fistula. Trans-fistula CEUS enhances the ultrasonic visibility of the fistula, branches, and internal opening. After injecting the contrast agent through the external opening, abundant microbubbles and the formation of liquid pressure leads to 
a strong acoustic reflection forming a high contrast between the fistula filled with finely dotted/line-like high-echoic sign and low-echoic wall. Thus, the direction and location of the fistula could be clearly defined. As the contrast agent flows along the fistula, it appears as high regional echoes when the microbubbles spill or enter the colon, which helps to correctly detect the internal opening. This study applied SonoVue ${ }^{\otimes}$ suspension as the contrast agent, which was different from the contrast agents used in previous studies (hydrogen peroxide) (10). SonoVue ${ }^{\circledR}$ is safe, rarely causes adverse reactions, does not hurt the rectal mucosa, and reduces the mucosal stimulation so that the injection site will be less painful and there will be lower sphincter tension. SonoVue ${ }^{\circledR}$ microbubbles are stable under alternating acoustic pressure, and ultrasound generates non-linear scattering to obtain better contrast enhancement. When microbubbles break, they are unable to form strong acoustic reflection, which causes the interruption in ultrasound examination.

However, trans-fistula CEUS is significantly more accurate than MRI in diagnosing the internal openings that are $<3 \mathrm{~cm}$ from the anal edge $(96.30 \%$ versus $87.65 \%$, $\mathrm{P}=0.043)$. There are two reasons that explain the occurrence of this difference. Firstly, intracavity biplane ultrasound is clearer in displaying low rectal mucosa and muscularis mucosa, which helps to locate the abnormal structure of this layer and improves the detection rate of the internal opening. Secondly, due to the loose parapharyngeal space located lower than the levator ani muscle, the infection spreads easily, leading to extensive effusion and conglutination in soft tissues and local fibrosis, and further causes the internal opening to be pseudo closed. When the contrast agent flows towards the internal opening, it generates pressure and re-opens a part of the closed internal opening.

This research had some limitations that should be noted. Firstly, the presence of an external opening was necessary to perform trans-fistula CEUS. However, this could cause some bias for anal fistula cases without an external opening. Secondly, trans-fistula CEUS may cause edema in the tissue space of the operating field. If surgery is not performed within 24 hours after trans-fistula CEUS, the internal opening is likely to close again. These reasons could influence the intraoperative diagnosis with respect to the internal opening. Lastly, there were few cases of upper sphincter fistulas and external sphincter fistulas, which could affect the results.

\section{Conclusions}

In summary, both trans-fistula CEUS and MRI presented high accuracy in the diagnosis of positioning of fistula according to Parks' classification and the internal opening. The trans-fistula CEUS exhibited better diagnostic value in the detection of internal openings that were $<3 \mathrm{~cm}$ away from the anal edge, and could provide surgeons with reliable evidence before surgery.

\section{Acknowledgments}

Funding: This work was supported by the Medical Scientific Research Foundation of Zhejiang Province, China (Grant No. 2019KY595).

\section{Footnote}

Reporting Checklist: The authors have completed the STARD reporting checklist. Available at https://dx.doi. org/10.21037/apm-21-1624

Data Sharing Statement: Available at https://dx.doi. org/10.21037/apm-21-1624

Conflicts of Interest: All authors have completed the ICMJE uniform disclosure form (available at https://dx.doi. org/10.21037/apm-21-1624). The authors have no conflicts of interest to declare.

Ethical Statement: The authors are accountable for all aspects of the work in ensuring that questions related to the accuracy or integrity of any part of the work are appropriately investigated and resolved. This study was approved by the ethics committee of Hwa Mei Hospital (YJ-KYSBNBEY-2018-034-01), and informed consent was obtained from all patients. The study was conducted in accordance with the Declaration of Helsinki (as revised in 2013).

Open Access Statement: This is an Open Access article distributed in accordance with the Creative Commons Attribution-NonCommercial-NoDerivs 4.0 International License (CC BY-NC-ND 4.0), which permits the noncommercial replication and distribution of the article with the strict proviso that no changes or edits are made and the original work is properly cited (including links to both the formal publication through the relevant DOI and the license). See: https://creativecommons.org/licenses/by-nc-nd/4.0/. 


\section{References}

1. Garg P. Is fistulotomy still the gold standard in present era and is it highly underutilized?: An audit of 675 operated cases. Int J Surg 2018;56:26-30.

2. Buchanan GN, Halligan S, Williams AB, et al. Magnetic resonance imaging for primary fistula in ano. $\mathrm{Br} \mathrm{J}$ Surg 2003;90:877-81.

3. Vergara-Fernandez O, Espino-Urbina LA. Ligation of intersphincteric fistula tract: what is the evidence in a review? World J Gastroenterol 2013;19:6805-13.

4. Buchanan GN, Williams AB, Bartram CI, et al. Potential clinical implications of direction of a trans-sphincteric anal fistula track. Br J Surg 2003;90:1250-5.

5. Garg P, Singh P, Kaur B, et al. Magnetic Resonance Imaging (MRI): Operative Findings Correlation in 229 Fistula-in-Ano Patients. World J Surg 2017;41:1618-24.

6. Halligan S, Stoker J. Imaging of fistula in ano. Radiology 2006;239:18-33.

7. Konan A, Onur MR, Özmen MN, et al. The contribution of preoperative MRI to the surgical management of anal fistulas. Diagn Interv Radiol 2018;24:321-7.

8. Sudoł-Szopińska I, Jakubowski W, Szczepkowski M, et al. Contrast-enhanced endosonography for the diagnosis of anal and anovaginal fistulas. J Clin Ultrasound 2002;30:145-50.

9. Sudol-Szopinska I, Szczepkowski M, Panorska AK, et al. Comparison of contrast-enhanced with non-contrast endosonography in the diagnostics of anal fistulas. Eur Radiol 2004;14:2236-41.

10. Tankova L, Tsankov Ts, Deredzhian Kh, et al. Contrastenhanced endoanal and transanal sonography for perianal

Cite this article as: Lin T, Ye Z, Hu J, Yin H. A comparison of trans-fistula contrast-enhanced endoanal ultrasound and MRI in the diagnosis of anal fistula. Ann Palliat Med 2021;10(8):91659173. doi: 10.21037/apm-21-1624 fistulas. Khirurgiia (Sofiia) 2005;(6):14-7.

11. Parks AG, Gordon PH, Hardcastle JD, et al. A classification of fistula-in-ano. Br J Surg 1976;63:1-12.

12. Vasilevsky CA, Gordon PH. The incidence of recurrent abscesses or fistula-in-ano following anorectal suppuration. Dis Colon Rectum 1984;27:126-30.

13. Emile SH, Elfeki $H$, Thabet $W$, et al. Predictive factors for recurrence of high transsphincteric anal fistula after placement of seton. J Surg Res 2017;213:261-8.

14. Sugrue J, Mantilla N, Abcarian A, et al. Sphincter-Sparing Anal Fistula Repair: Are We Getting Better? Dis Colon Rectum 2017;60:1071-7.

15. Dudukgian H, Abcarian H. Why do we have so much trouble treating anal fistula? World J Gastroenterol 2011;17:3292-6.

16. Liang $\mathrm{C}, \mathrm{Lu} \mathrm{Y}$, Zhao B, et al. Imaging of anal fistulas: comparison of computed tomographic fistulography and magnetic resonance imaging. Korean J Radiol 2014;15:712-23.

17. Orsoni P, Barthet $M$, Portier F, et al. Prospective comparison of endosonography, magnetic resonance imaging and surgical findings in anorectal fistula and abscess complicating Crohn's disease. Br J Surg 1999;86:360-4.

18. Schwartz DA, Wiersema MJ, Dudiak KM, et al. A comparison of endoscopic ultrasound, magnetic resonance imaging, and exam under anesthesia for evaluation of Crohn's perianal fistulas. Gastroenterology 2001;121:1064-72.

(English Language Editor: A. Kassem) 